Article

\title{
Field Tests on Eco-Friendly Railway Precast Concrete Slab
}

\author{
Taehoon Koh ${ }^{1}$ and Moochul Shin ${ }^{2, *(\mathbb{D})}$ \\ 1 Advanced Railroad Civil Engineering Division, Korea Railroad Research Institute, Gyeonggi 16105, Korea; \\ thkoh@krri.re.kr \\ 2 Department of Civil and Environmental Engineering, Western New England University, \\ Springfield, MA 01119, USA \\ * Correspondence: moochul.shin@wne.edu; Tel.: +1-413-796-2202
}

Received: 28 May 2020; Accepted: 12 June 2020; Published: 16 June 2020

check for updates

\begin{abstract}
This study focuses on evaluating the field performance of a newly developed eco-friendly precast concrete slab track structure for railway/subway systems in Seoul, South Korea. Although Ballasted railway track structures are one of the most common track structures in the railway industry, they have some drawbacks including higher maintenance cost, un-uniform supports, and a high level of noise and vibration. However, a ballastless (slab-based) track structure system requires less maintenance and uniform support conditions, as well as several ballastless structure systems developed for high-speed trains. The Seoul Metro subway in South Korea has developed a ballastless reinforced concrete $(\mathrm{RC})$ slab railway system using a type of conventional concrete. This study presents a ballastless precast concrete slab using a newly developed eco-friendly concrete, which can significantly improve structural performances and the manufacturability of a railway track structure system. This study evaluates the field performance of the eco-friendly concrete slab system deployed in one of the existing tunnel sections of the Seoul Metro subway system. A total of $10 \mathrm{~m}$ long slab sections including a $5 \mathrm{~m}$ long eco-friendly "ballasted track to slab track (B2S)" panels section and a $5 \mathrm{~m}$ long conventional B2S panels section are installed and monitored side by side. Field tests are performed to measure the level of noise, vibration, dynamic wheel load, rail displacement, and rail stress. The field measurements from the eco-friendly B2S section are compared to those of the conventional reinforced concrete slab track systems. The results show that the performance of the new B2S system using the eco-friendly concrete is comparable and/or superior to the conventional system.
\end{abstract}

Keywords: Eco-friendly concrete; ground granulated blast furnace (GGBF) slag; electric arc furnace (EAF) oxidizing slag; ballasted track to slab track (B2S)

\section{Introduction}

In the railway engineering field, two basic types of railroad track structures are most commonly used: (1) a ballasted railway track structure with either concrete prestressed sleepers or wooden sleepers and (2) a ballastless track structure. Over several decades, the ballasted track structure has been widely used as one of the important track structure systems. However, the ballasted system has inherent drawbacks such as (1) ballast fouling, (2) uneven support conditions to the track structures, and (3) negative effects on ties and rails. Ballast fouling is identified as one of the main causes that can negatively affect the integrity of the track structure [1]. Therefore, it has been of great interest to evaluate and detect the level of fouled ballast and its condition. A non-destructive testing method using ground penetration radar (GPR) has been developed and its great potential has been presented in the railway industry [1,2]. The fouled-ballast greatly affects the drainage capacity of the railway infrastructure [3]. After investigating derailment accidents (e.g., accident no. DCA13FR009 in Bronx, 
New York, NY, USA on 18 July 2013), the investigation report indicated that the accidents were associated with the damage of concrete sleepers including reduced the cross-section of the ties due to abrasion, fouling, and others [4,5]. Recent studies have focused on identifying different failure mechanisms of prestressed concrete crossties including splitting/bursting, center biding, and rail seat deterioration [6-10]. In order to ensure the structural integrity and the safety of the track structure including substructures and superstructures, a ballasted track requires high maintenance cost.

As opposed to the ballasted track, the maintenance cost of a continuous, ballastless, or slab track is lower than the traditional ballasted track, although it initially requires higher construction costs [11,12]. Recently, field applications of a slab track have become more popular in Japan, South Korea, China, and Europe, since a slab track system shows superior performance such as higher longitudinal and lateral resistance, less buckling issue, even substructure settlements etc. [13]. In addition to the high-speed train applications, a slab track has been used for special track systems such as tunnel, bridges, and transit $[11,14,15]$.

As the loading demands have increased over the last decades, in addition to the interest of increasing speed for a high-speed train system with an environmentally-sustainable next-generation railroad track system in South Korea, the authors developed an eco-friendly concrete, which was adopted to develop an eco-friendly railroad structural component. The developed eco-friendly concrete utilizes the industry slags (i.e., ground granulated blast furnace slag and electric arc furnace oxidizing slag) while minimizing the amount of cement and natural resource usages $[16,17]$. Therein, $30 \%$ of Portland type III cement was replaced by ground granulated blast furnace (GGBF) slag and $100 \%$ of fine aggregate was replaced by electric arc furnace (EAF) oxidizing slag. They used the newly developed cement-based material to manufacture eco-friendly prestressed concrete sleepers and the new railway structural component was successfully installed in the field of a high-speed train track in South Korea. They conducted a series of experimental tests to evaluate the structural performance of the eco-friendly concrete sleepers and compared to conventional prestressed concrete sleepers according to domestic/international standard tests. Static and dynamic load tests were performed and the test results demonstrated that the bending capacity and crack initiation of the eco-friendly concrete sleepers were higher and much delayed as compared to the conventional sleepers [16]. In addition, the authors measured the transfer length of the developed eco-friendly concrete sleepers, since it was critical for the railseat section to have fully developed effective stress after de-tensioning tendons. If the transfer length was longer than the railseat area, the railseat section would be subjected to premature failures. They used the $95 \%$ average maximum strain (AMS) method to determine the transfer length. The transfer length of the eco-friendly concrete sleepers was not only shorter than that of the conventional concrete sleepers but shorter than the length measured from the edge of the sleeper to the beginning of the railseat section, which indicated that the effective stress was fully developed in the railseat section [17]. The eco-friendly concrete not only reduced the $\mathrm{CO}_{2}$ emission by replacing $30 \%$ of cement but also exhibited superior mechanical performance, which was attributed to stable and dense microstructures and improved workability (ball bearing effect) by using the EAF oxidizing slag and improved durability by using the GGBF slag [18] in addition to the higher 28-day minimum compressive strength.

In order to maximize the benefits of the developed eco-friendly concrete, this paper presents the development of an eco-friendly precast concrete slab. Four eco-friendly ballasted track to slab track (B2S) panels are manufactured and installed in an operating metro-subway line in Seoul, South Korea and the field performance is measured: dynamic wheel loads, rail displacements, rail stress, and the level of noise and vibration. The measurements are compared with the performance of a conventional reinforced concrete slab section which was installed right next to the eco-friendly B2S.

\section{B2S Panel}

This study adopts one of the conventional reinforced concrete (RC) slab designs used by the Seoul Metro subway. Figure 1 shows a 3D rendering image of the B2S panel. Its dimensions were $2.75 \mathrm{~m}$ 
(width) $\times 1.225 \mathrm{~m}$ (length) $\times 0.17 \mathrm{~m}$ (thickness). An elastic fastening system was used to connect the rails to the slab panel. The B2S reinforced concrete adopted by the Seoul Metro subway system required us to use the minimum compressive strength of $50 \mathrm{MPa}$ concrete in order to meet its design criteria [19]. Their standard was established to minimize the settlement of the track structure, especially the subsoil. The B2S track system had a higher track stiffness than a ballasted track structure with prestressed concrete sleepers. In addition, Kong et al. reported that the installed B2S track structure system in the Seoul Metro subway reduces the noise and vibration level as compared with the ballasted track structure [20].

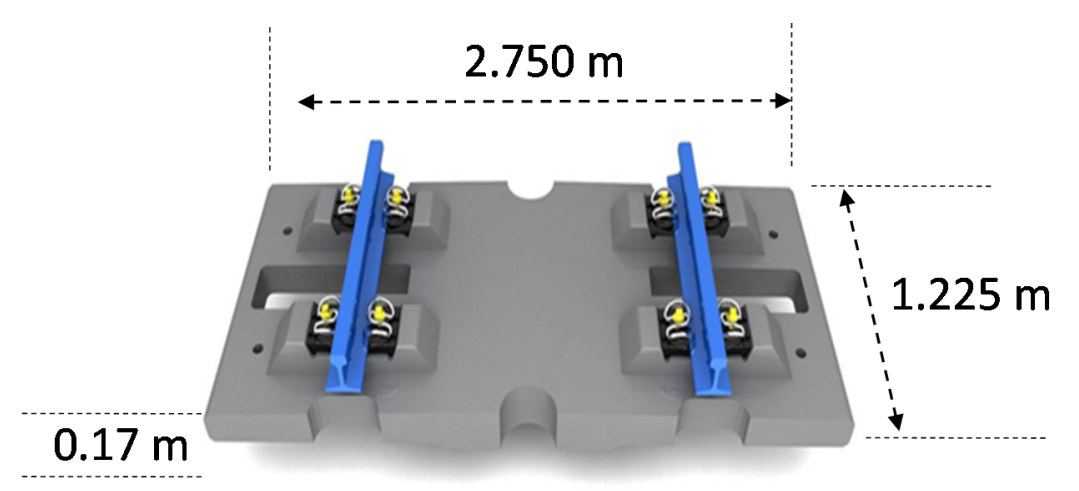

Figure 1. A 3D rending image of a ballasted track to slab track (B2S) panel.

Given the geometric design, two types of B2S panels were fabricated with (1) a conventional concrete (minimum 28-day compressive strength, $f^{\prime} c=50 \mathrm{MPa}$ ) and (2) the eco-friendly concrete (minimum 28-day compressive strength, $f^{\prime} c=70 \mathrm{MPa}$ ). Hereafter, the first panel with a conventional concrete is named "Conventional B2S panel," and the second panel with the eco-friendly concrete is named "Eco-friendly B2S panel."

Figure 2 shows the pictures of the fabrication process of the B2S panels: (1) \#3 and \#4 rebars were assembled in a steel formwork (see Figure 2a), (2) concrete was poured into the formwork, (3) concrete was cured at the ambient temperature, and finally, Figure $2 \mathrm{~d}$ shows the prototype of two eco-friendly B2S panels. Normally the conventional concrete takes at least seven days to reach the design strength (50 MPa). However, the eco-friendly concrete can reach a strength of $50 \mathrm{MPa}$ within one day. In order to develop the high-early strength concrete, the eco-friendly concrete used the Portland type III cement and GGBF slag together as the cement-binder. The water to cement-binder ratio was 0.35 . In addition, it is worthwhile to note that the self-weight of the eco-friendly concrete was at least $10 \%$ heavier than the conventional concrete, since the density of the EAF slag $\left(3.4 \mathrm{~g} / \mathrm{cm}^{3}\right)$ is heavier than natural fine aggregate $\left(2.6 \mathrm{~g} / \mathrm{cm}^{3}\right)$. The more detail of the eco-friendly concrete can be found in previous studies $[16,17]$. 


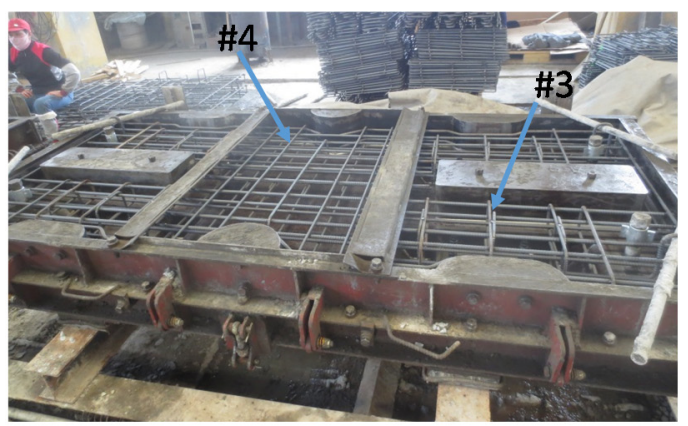

(a) Rebar assembly

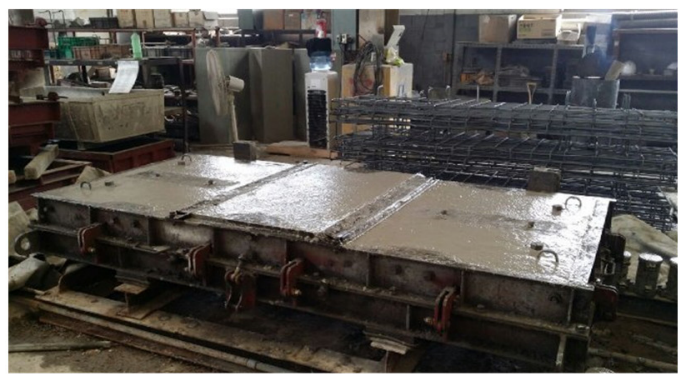

(c) Curing

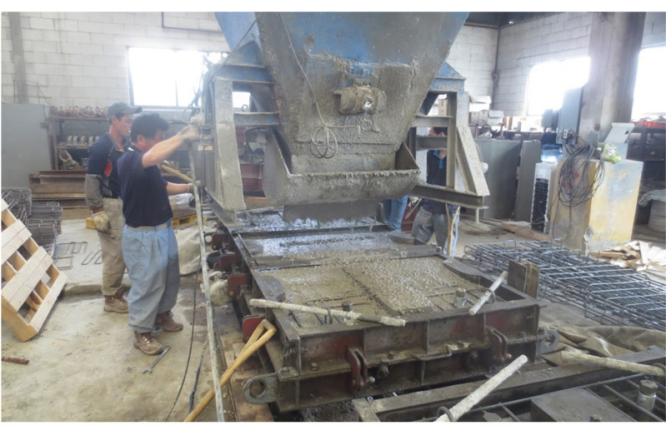

(b) Pouring concrete

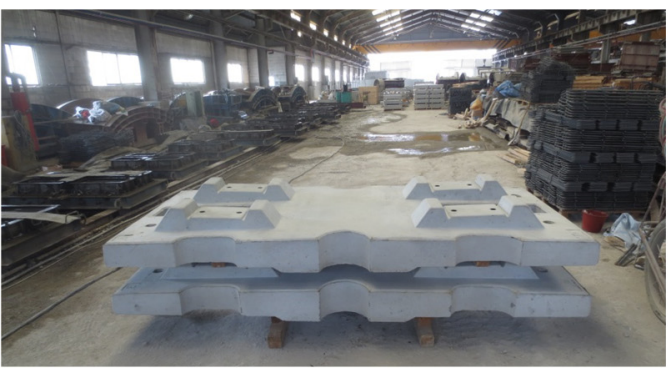

(d) Prototype of the B2S panels

Figure 2. Fabrication process of the B2S panels: (a) Rebar assembly, (b) Pouring concrete, (c) Curing, and (d) Prototype of the B2S panels.

\section{Field Test Set-Up}

\section{Installation of the B2S Panels}

A total of eight concrete slabs were installed in a tunnel of the operating Seoul subway lines (i.e., Line \#1): four ecofriendly B2S panels and four conventional B2S panels. The total length of the tested B2S panels was $10 \mathrm{~m}$. This line passed through a residential area. In this field tests, the performance of the eco-friendly B2S panels such as structural behaviors and a noise level were measured and compared with the conventional panels. For the selection of the field-testing site, some conditions were carefully considered: (1) the same rail profile without any irregularity; (2) a section of the lines without acceleration and deacceleration for trains; (3) same geometry including the cant and radius of the line; and (4) the same train speed. The first $5 \mathrm{~m}$ section consisted of four conventional B2S panels and the next $5 \mathrm{~m}$ section consisted of four eco-friendly B2S panels. The field installation process followed four steps: (1) removal of the ballast, (2) panel installation, (3) pouring the fillers between panels, and (4) completion of the installation. Figure 3 shows the installation process of 8-B2S panels in the operational line. The installation of the panels took place after the regular operation hours in order to minimize the obstruction of the operation of the subway line.

Strain gauges, accelerometers, and linear voltage differential transducers (LVDTs) were mounted on the rails, tunnel walls, and the B2S panels. Those sensors were installed to measure vertical and lateral wheel loads, rail bottom stress, vertical and lateral displacements, vertical acceleration of panels, and lateral acceleration of tunnel walls. Figure 4 shows the plan view and sectional view of the schematics of the sensor locations of the field-testing site. 


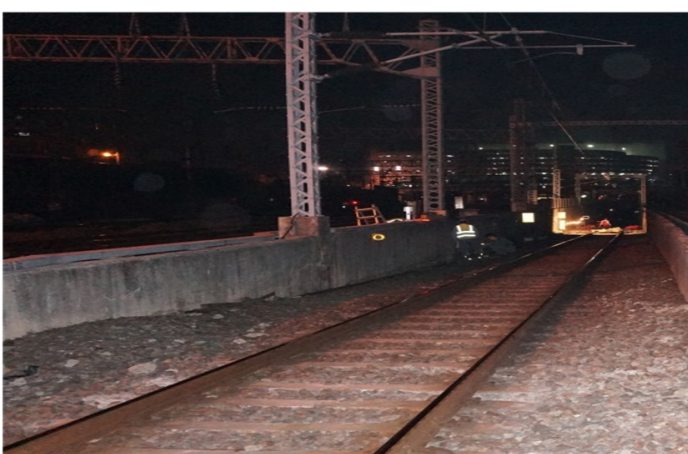

(a) Before removing the ballast

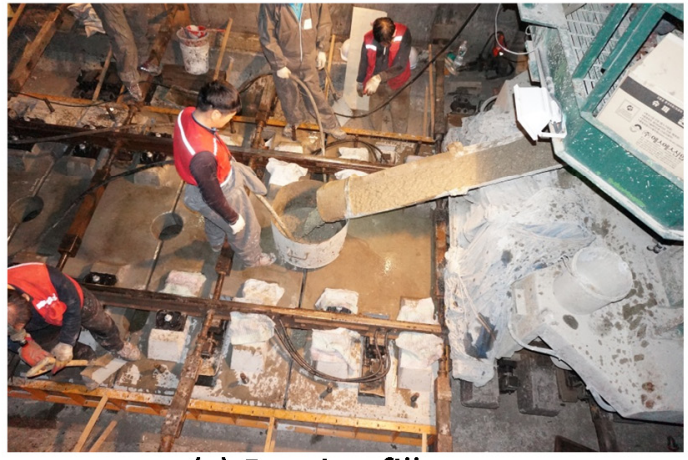

(c) Pouring fillers

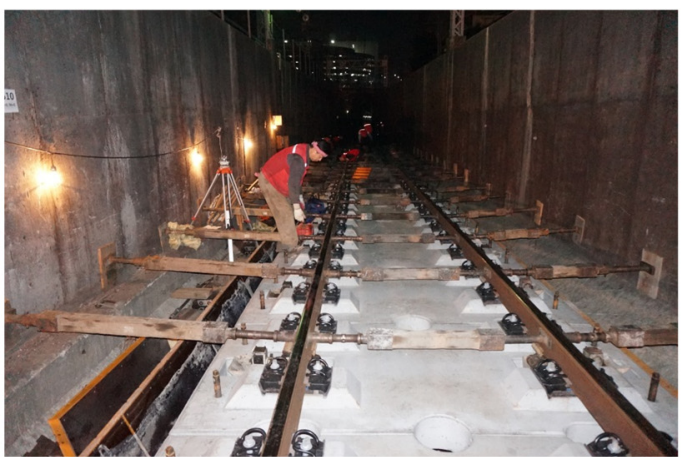

(b) Installation of panels

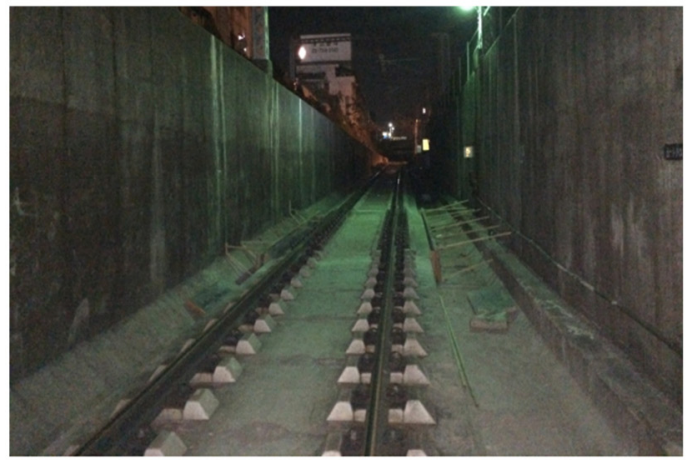

(d) Completion of the installation

Figure 3. Installation process of the B2S panels: (a) Before removing the ballast, (b) Installation of panels, (c) Pouring fillers, and (d) Completion of the installation.

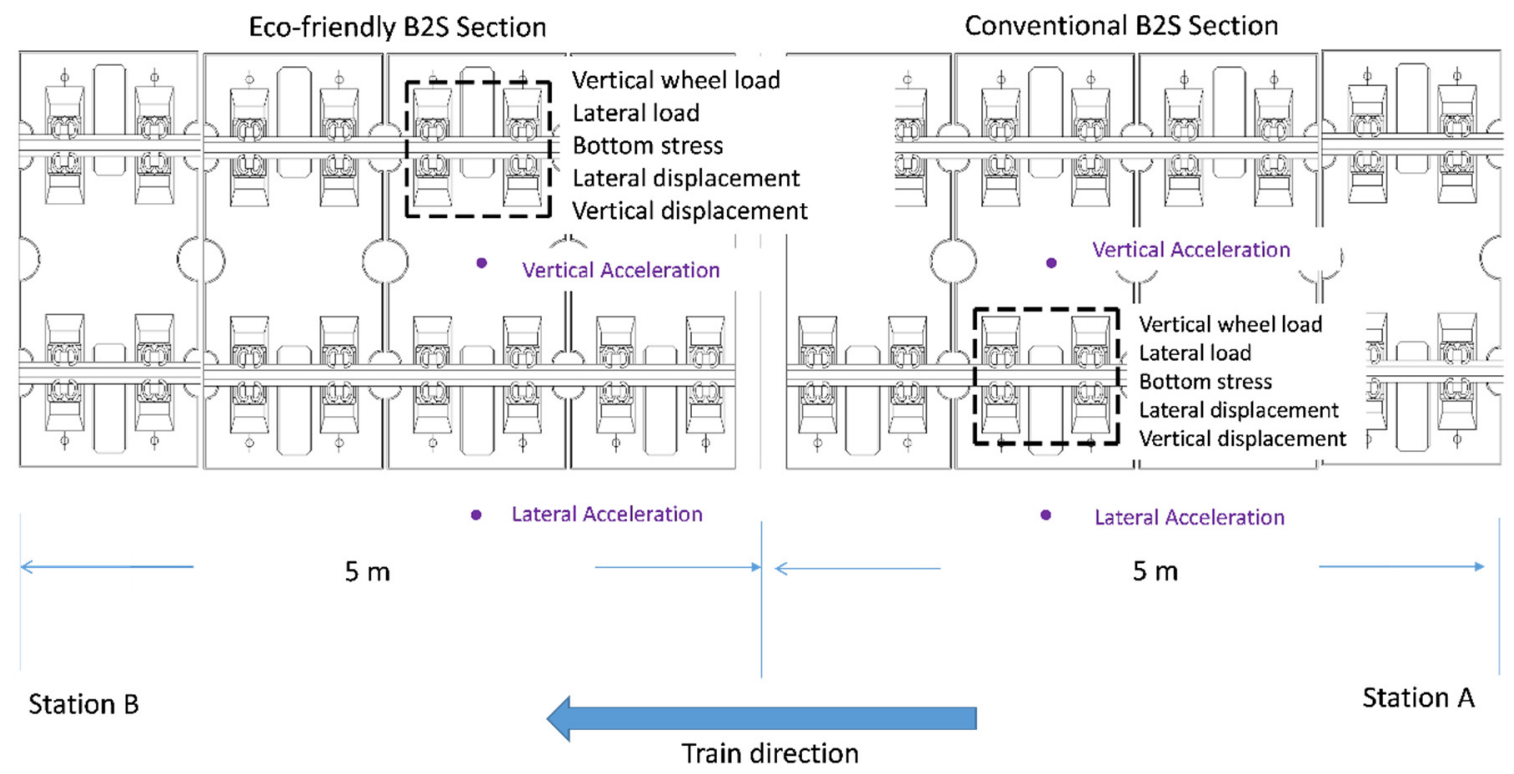

Figure 4. Sensor implementation plan.

Figure 5 shows a picture of the installed sensors to measure wheel loads, displacements, stress, and accelerations. 


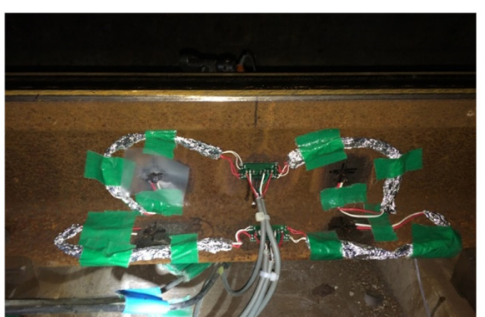

(a) Wheel loads

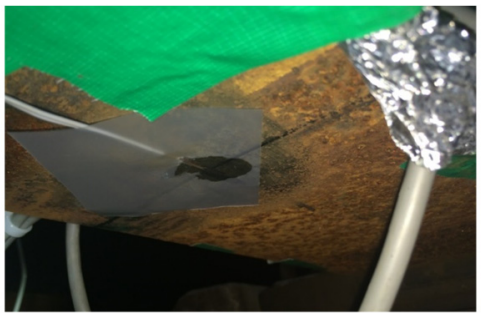

(c) Rail stress

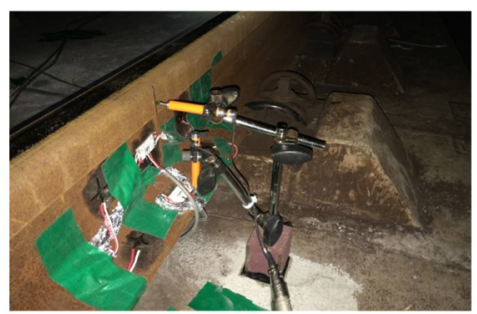

(b) Rail displacements

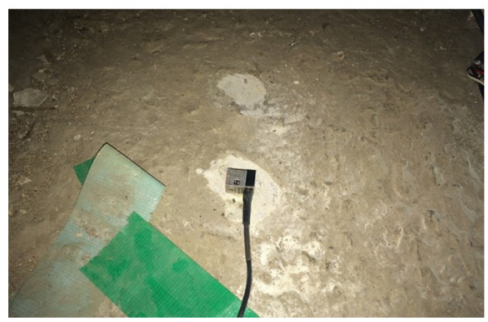

(d) Accelerometer

Figure 5. Pictures of instrumented sensors on site: (a) vertical and lateral wheel loads, (b) rail displacements using linear voltage differential transducers (LVDTs), (c) rail stress on a bottom surface of rail, and (d) accelerometer on a panel.

Four strain gauges (full bridge) mounted on the surface of the rail to measure vertical and lateral loads (see Figure 4 Sensor implementation plan). The static vertical and lateral wheel load calibrations were conducted. Figure 6 shows the vertical wheel load calibration test. A hydraulic jack was used to apply a known vertical load with the increment of $10 \mathrm{kN}$. The calibration test was repeated three times. A linear regression analysis was carried out to obtain the calibrated relation between the vertical load and the strain change. This calibrated relation was used to measure the dynamic wheel load (Figure 6b).

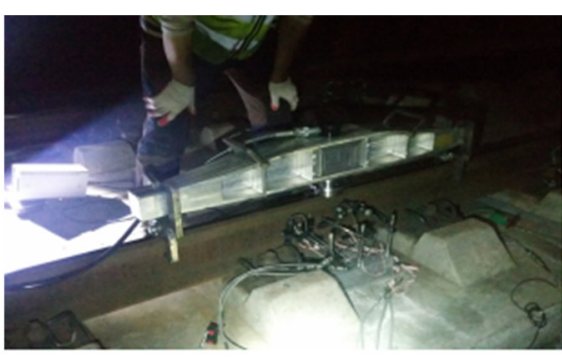

(a)

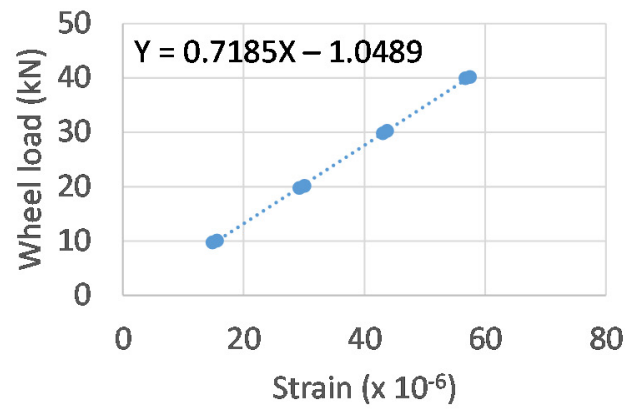

(b)

Figure 6. A vertical wheel load calibration test (a) and the calibration relation (b).

\section{Field Test Results}

A portable data acquisition logger (EDX-100A) with 32 channels together with bridge boxes were used to obtain the field data $(1 \mathrm{kHz})$. Figure 7 shows a photo of a subway train running on the testing site. A field test was conducted under 11 different trains. The speed of the trains ranged from $31-47 \mathrm{~km} / \mathrm{h}$. The average speed and the standard deviation were $38.3 \mathrm{~km} / \mathrm{h}$ and $4.2 \mathrm{~km} / \mathrm{h}$, respectively. Table 1 summarizes the measured speed $(\mathrm{km} / \mathrm{h})$ of each run. 


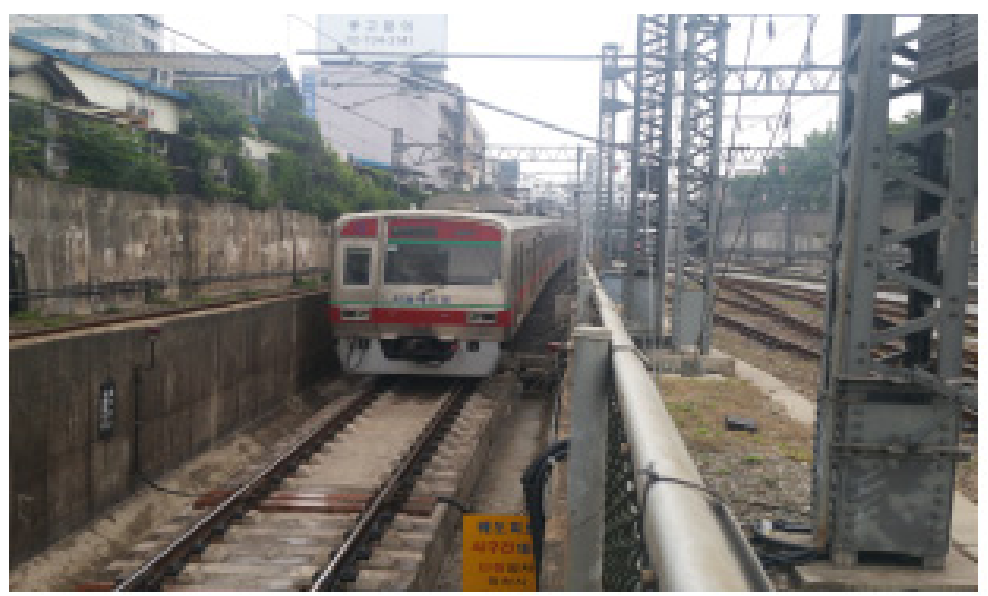

Figure 7. A photo of a subway train on the field-testing site.

Table 1. Measured speed of each test run.

\begin{tabular}{cccc}
\hline & Speed (km/h) & & Speed (km/h) \\
\hline Run \#1 & 39 & Run \#7 & 41 \\
Run \#2 & 35 & Run \#8 & 39 \\
Run \#3 & 36 & Run \#9 & 31 \\
Run \#4 & 36 & Run \#10 & 47 \\
Run \#5 & 38 & Run \#11 & 37 \\
Run \#6 & 42 & Average Speed & 38.3 \\
\hline
\end{tabular}

\subsection{Dynamic Wheel Loads}

Figure 8 shows the comparisons of the specific time history of the dynamic vertical wheel load measured from the eco-friendly B2S panel and the conventional B2S panel, respectively. As shown in the graphs in Figure 8, the change of the vertical load due to the use of the eco-friendly B2S was minimal. Throughout the 11 runs of the field test, the maximum recorded dynamic vertical loads were $76.68 \mathrm{kN}$ and $76.92 \mathrm{kN}$ for the eco-friendly B2S and conventional B2S, respectively. In addition, the average vertical loads were found to be 69.4 (eco-friendly B2S) and $71.2 \mathrm{kN}$ (conventional B2S). Figure 9a shows the comparison between the maximum vertical load measured from the eco-friendly and conventional slabs under 11 runs. $t$-test results $(p=0.260)$ also show that there was no statistical difference between the dynamic vertical loads measured from each slab. In addition, the dynamic vertical wheel loads were presented with respect to the speed. Figure $9 \mathrm{~b}$ indicates that the change of the dynamic vertical load was minimal as the speed of the trains increases for both B2S panels. The eco-friendly B2S showed slightly less dynamic vertical wheel loads than those measured from the conventional B2S. Therefore, the eco-friendly B2S panels would not increase the vertical load demand on rail and track structure.

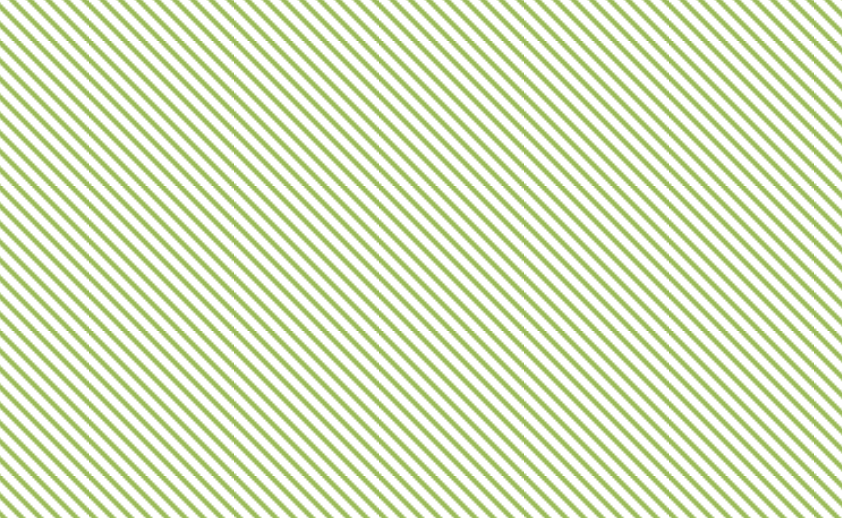

Figure 8. Time history graphs of the dynamic vertical wheel load. 


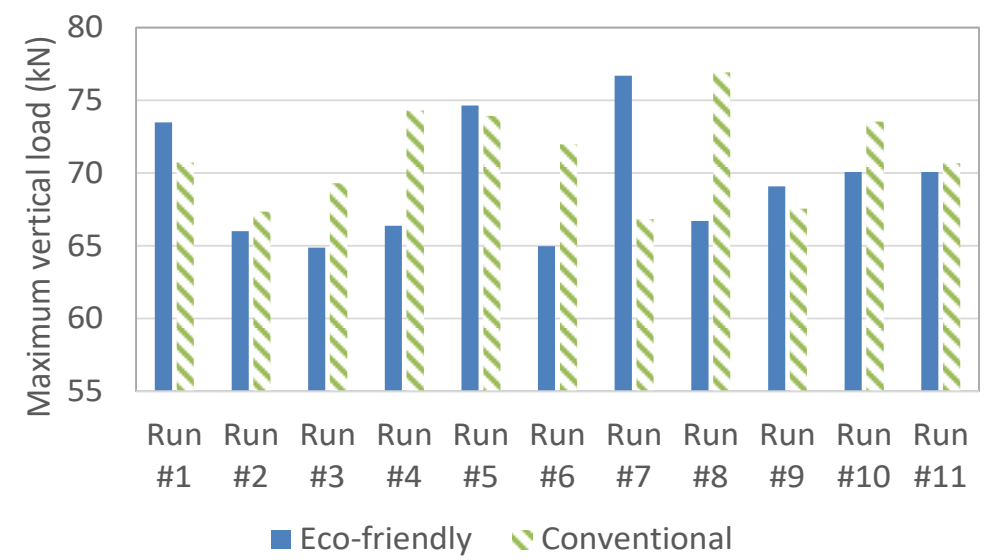

(a)

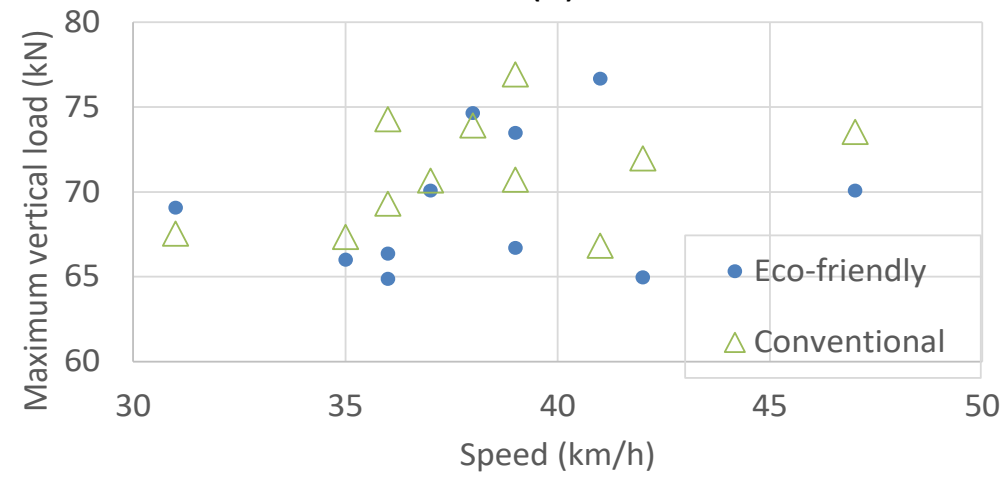

(b)

Figure 9. The maximum vertical loads under each run (a) and vs. speed (b).

Lateral loads were also measured. The maximum measured lateral loads were $7.55 \mathrm{kN}$ and $6.98 \mathrm{kN}$ for the eco-friendly B2S and the conventional B2S, respectively. The average lateral loads were $5.83 \mathrm{kN}$ from the eco-friendly B2S and $4.24 \mathrm{kN}$ from the conventional B2S. The Korean railway track design guideline recommends that the lateral load to vertical load (L/V) ratio should be less than 0.8 to prevent any derailment due to any excessive lateral loads [21]. Figure 10 shows the computed average $\mathrm{L} / \mathrm{V}$ ratio. The average $\mathrm{L} / \mathrm{V}$ ratios for the eco-friendly B2S and conventional B2S panels were 0.08 and 0.04 , respectively. Since the measurement was taken on the tangent line, both measured L/V ratios were insignificant and satisfied the standard.

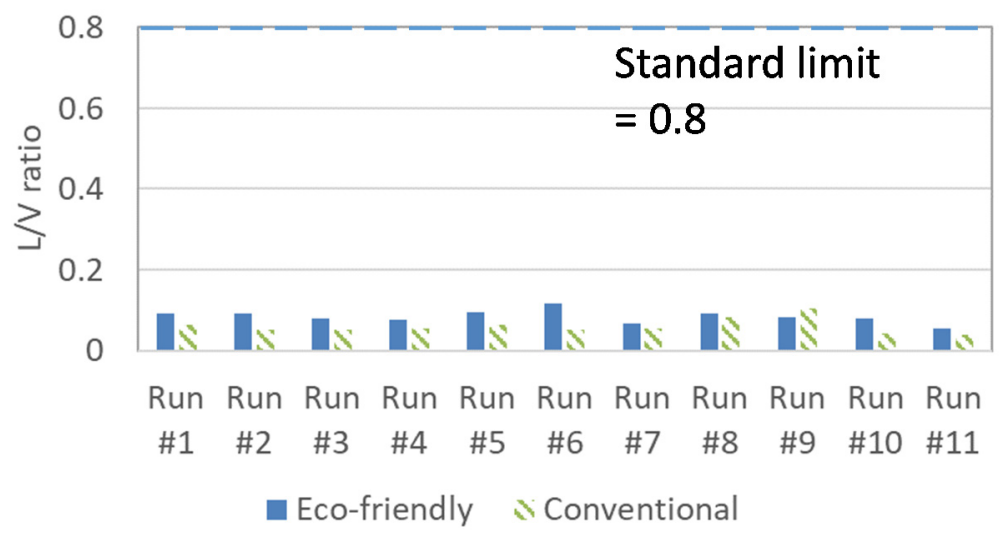

Figure 10. Average vertical load (L/V) ratio. 


\subsection{Rail Displacements and Track Stiffness}

The vertical displacements of the rails were measured for the eco-friendly panel and the conventional panel. Under 11 runs, the maximum displacement of $1.28 \mathrm{~mm}$ and $1.29 \mathrm{~mm}$ was obtained for the eco-friendly and conventional B2S, respectively, while the average displacement of $1.12 \mathrm{~mm}$ (eco-friendly) and $1.19 \mathrm{~mm}$ (conventional) was recorded. Figure 11 compares the maximum vertical displacements recorded from each slab. With the recorded maximum vertical wheel loads and displacements, the track stiffness $K_{t}$ of each system was computed by Equation (1).

$$
K_{t}=\frac{Q_{d y n}}{\delta_{\max }}
$$

where $Q_{d y n}$ is the maximum vertical wheel load and $\delta_{\max }$ is the maximum displacement.

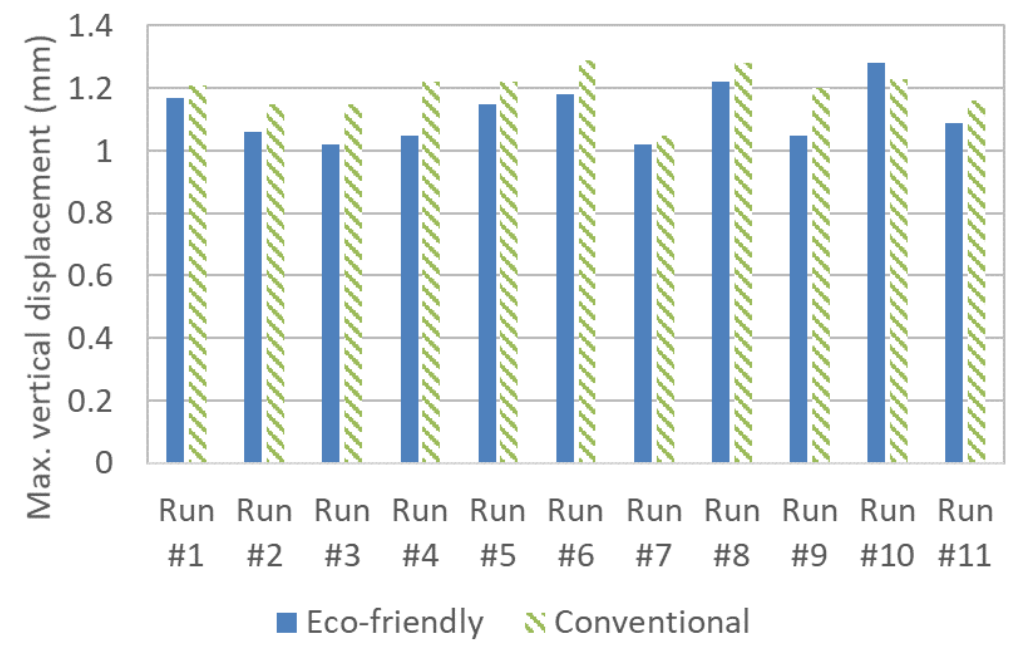

Figure 11. The maximum vertical displacement.

Figure 12 compares the measured track stiffness of the two systems. The measured track stiffness of the eco-friendly and the conventional B2S was $62.4 \mathrm{kN} / \mathrm{mm}$ and $59.6 \mathrm{kN} / \mathrm{mm}$, respectively. Although the track stiffness of the eco-friendly B2S was slightly higher than that of conventional B2S, this result shows that the change of the dynamic response of the two systems was minimal. The $t$-test result ( $p=0.165$ ) on the track stiffness also indicates that the difference between the two systems was statistically insignificant.

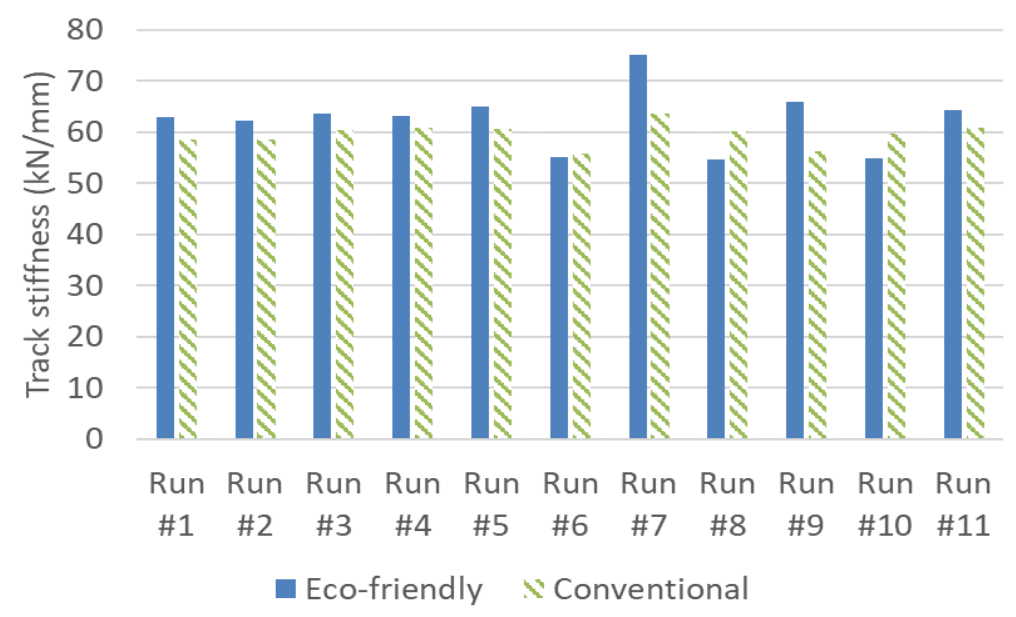

Figure 12. The measured track stiffness. 
The lateral displacement was an important measurement to ensure the safety of the track. When the lateral displacement was too great, a derailment accident would occur. The Seoul Metro subway system used the standard gage length of $1435 \mathrm{~mm}$. The Korean Railroad Standards states that the maximum lateral displacement of the head of rail shall not be greater than $4.00 \mathrm{~mm}$ [21]. Figure 13 shows the comparison between the maximum lateral displacements measured from the eco-friendly B2S and the conventional B2S. The maximum lateral displacement of $0.40 \mathrm{~mm}$ and $0.51 \mathrm{~mm}$ was recorded for the eco-friendly B2S panel and conventional panel, respectively. The maximum and average lateral displacements of both panels met the standard limit $(4.0 \mathrm{~mm})$.

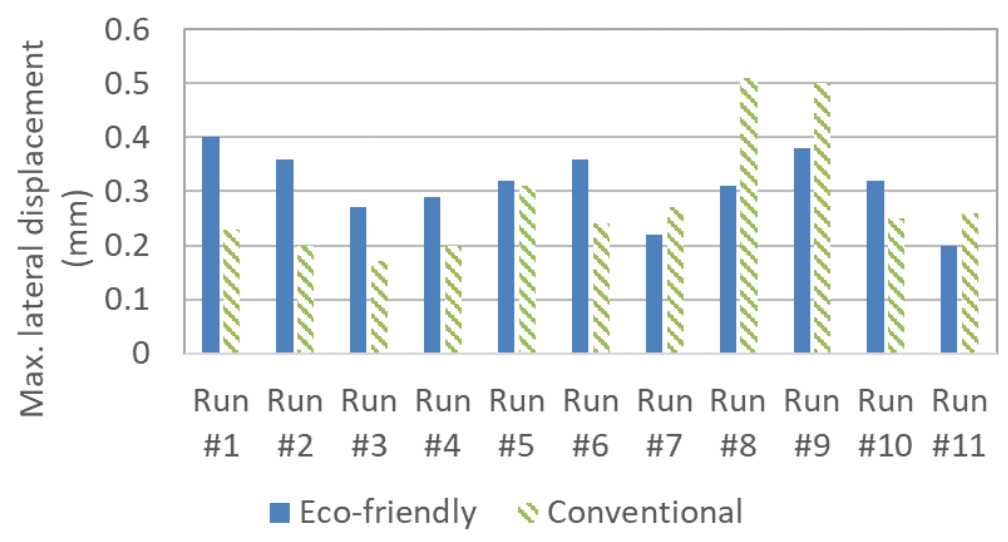

Figure 13. The maximum lateral displacement.

\subsection{Rail Bottom Stress}

The rail standard required by the Seoul Metro subway system states that the maximum train-induced stress on the bottom surface of rail shall not be greater than $92 \mathrm{MPa}$. The tensile stress was monitored and recorded for both B2S panels. Figure 14 shows a comparison between the maximum rail bottom stress between the two systems. The maximum bottom rail stress was $39.5 \mathrm{MPa}$ and 42.9 MPa for the eco-friendly B2S and conventional B2S, respectively. The average tensile stress measured on the bottom surface of the rails was $32.1 \mathrm{MPa}$ (eco-friendly) and $35.1 \mathrm{MPa}$ (conventional), respectively. The maximum stress was only $43 \%$ (eco-friendly) and $47 \%$ (conventional) of the standard limit (92 MPa). While both cases meet the standard, the demand on the rail in terms of the bending stress was slightly less when using the eco-friendly B2S. Figure 15 shows the time history of the measured rail bottom stress from both panels. The measured rail bottom stress from the eco-friendly B2S was compatible with the conventional B2S system. The t-test result $(p=0.125)$ indicates the difference between the two systems in terms of the rail bottom stress was statistically insignificant.

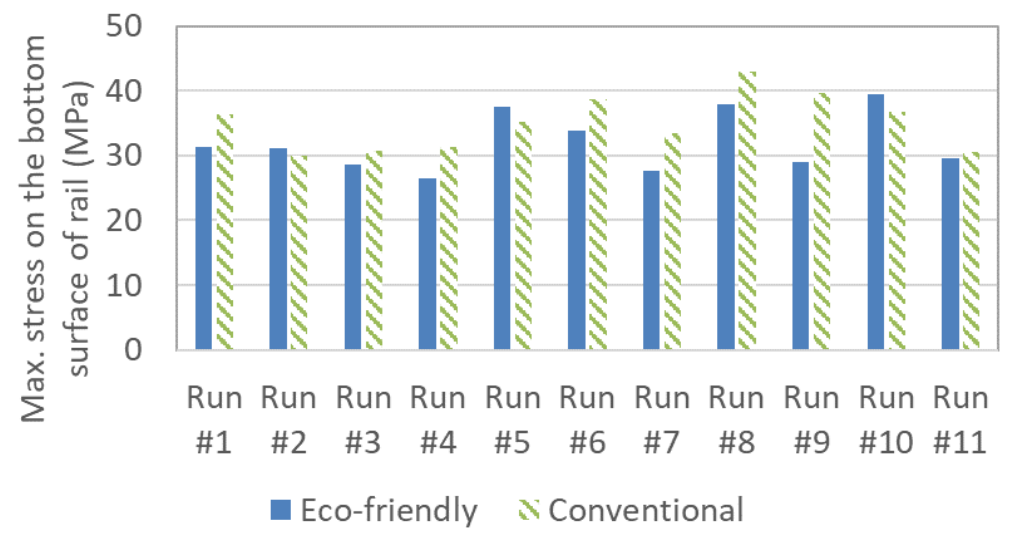

Figure 14. Maximum rail bottom stress. 


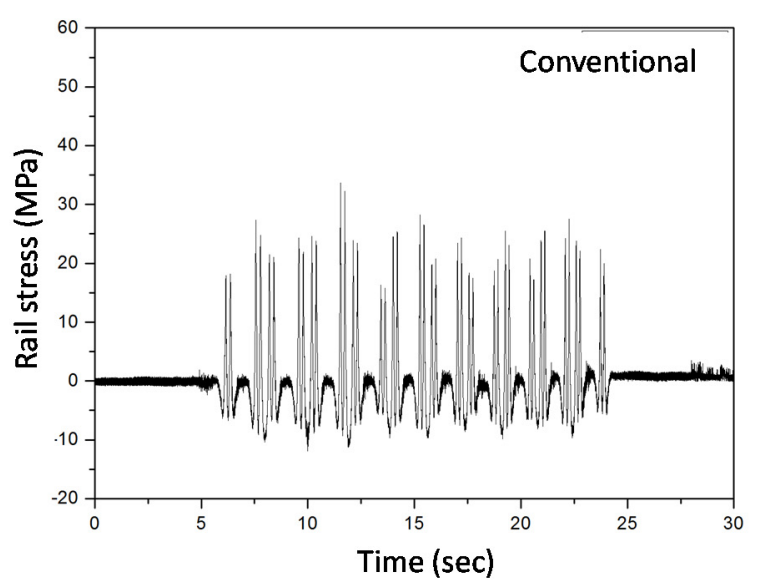

(a)

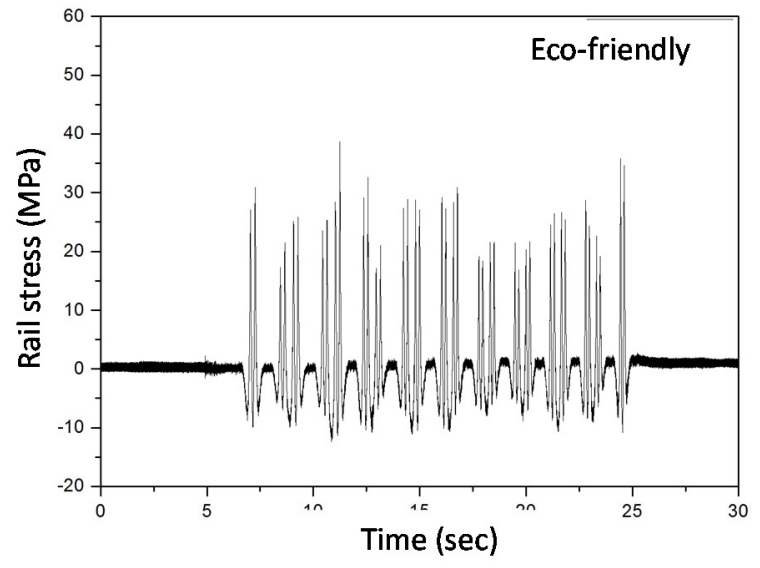

(b)

Figure 15. Time history of the stress on the bottom surface of rail: (a) conventional B2S and (b) eco-friendly B2S.

\subsection{Accelerations and Noise}

Vertical accelerations on the B2S panels and lateral accelerations on the tunnel wall were monitored. Figure 16 shows the comparison of the vertical acceleration between the eco-friendly B2S and the conventional B2S. Some of the acceleration records from the conventional B2S were slightly higher than those obtained from the eco-friendly B2S. The average vertical acceleration was found to be $0.0318 \mathrm{~g}$ and $0.0361 \mathrm{~g}$ for the eco-friendly and the conventional B2S, respectively. In addition, Figure 17 shows the comparison of the lateral acceleration on the tunnel walls. The average lateral acceleration was $0.0156 \mathrm{~g}$ (eco-friendly) and $0.0152 \mathrm{~g}$ (conventional). The difference in the lateral accelerations was relatively small. The $t$-test results on the vertical acceleration and the lateral acceleration were $p=0.256$ and $p=0.808$, respectively. Figure 18 shows the time history graphs of the vertical accelerations as an example. By using the eco-friendly B2S panels, the dynamic characteristics of the track structure did not significantly change. It is worthwhile to note that some of the data were lost during the field test (e.g., acceleration data from runs \#7 and \#11).

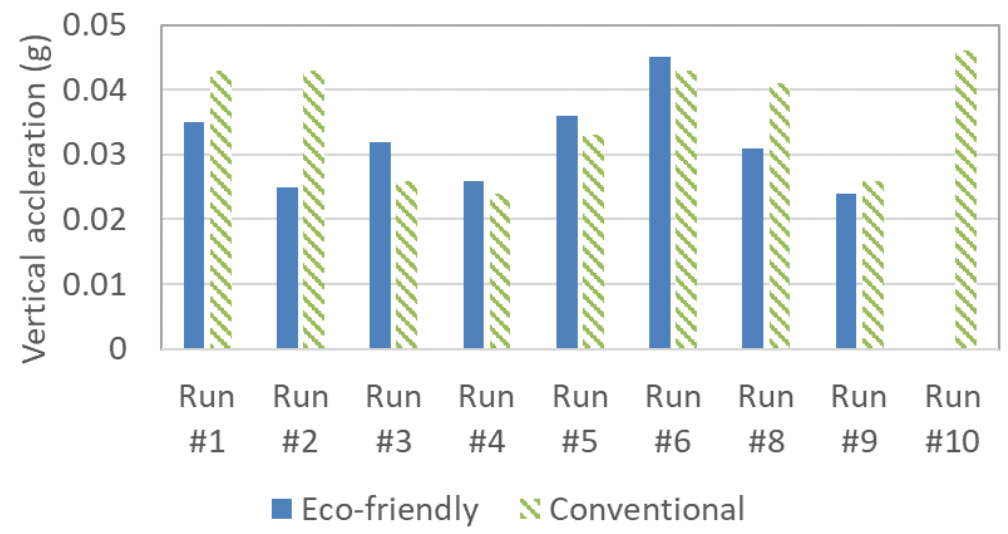

Figure 16. Vertical accelerations on the B2S panels.

By using the time-history acceleration data, a $1 / 3$ octave analysis was conducted in order to evaluate the noise level. Since the Seoul Metro subway system serves many parts of residential areas of Seoul, South Korea, it was imperative to monitor and reduce the noise level of the track infrastructure when a train passed through/by areas. Figures 19 and 20 show the $1 / 3$ octave analysis results on the acceleration levels $(\mathrm{dB})$. The average noise levels measured on the slab floor and the tunnel wall for the eco-friendly B2S were $70.5 \mathrm{~dB}$ and $65.1 \mathrm{~dB}$, while the average noise levels for the conventional B2S were $72.4 \mathrm{~dB}$ and $67.1 \mathrm{~dB}$. As the figures indicate, the noise levels obtained from the eco-friendly 
B2S were slightly less than the conventional B2S. The range of the noise reduction effect due to the distance for the eco-friendly and the conventional B2S was 3.14-7.43 dB and 3.18-9.38 dB, respectively. The noise and vibration analysis results demonstrated that the eco-friendly B2S system is as effective as the conventional B2S system. The previous study indicates that the conventional B2S system can significantly reduce the noise level compared to the ballasted track structure system with concrete sleepers [20].

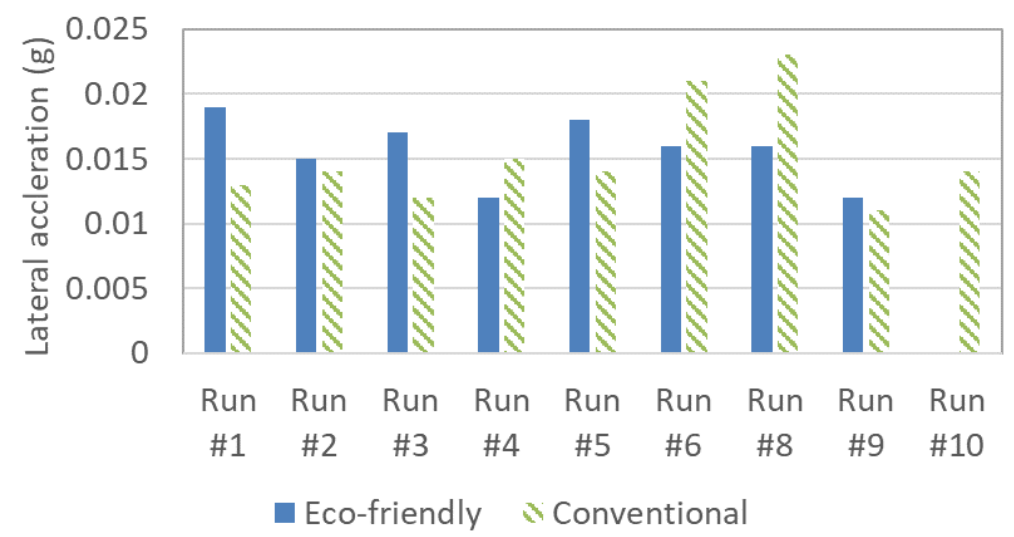

Figure 17. Lateral accelerations on the tunnel wall with respect to speed.

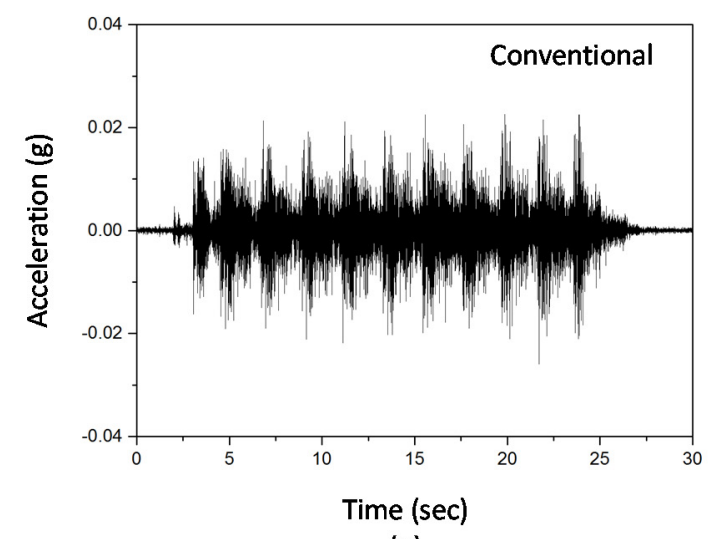

(a)

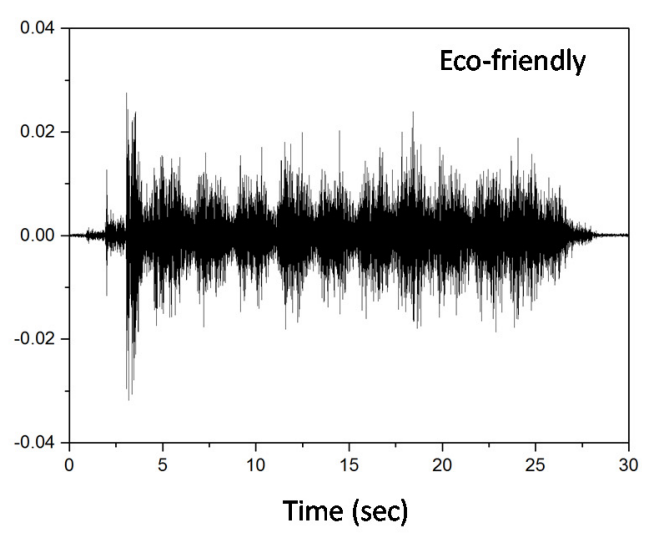

(b)

Figure 18. Time history graph of the vertical acceleration recorded on the B2S panels: (a) Conventional B2S and (b) Eco-friendly B2S.

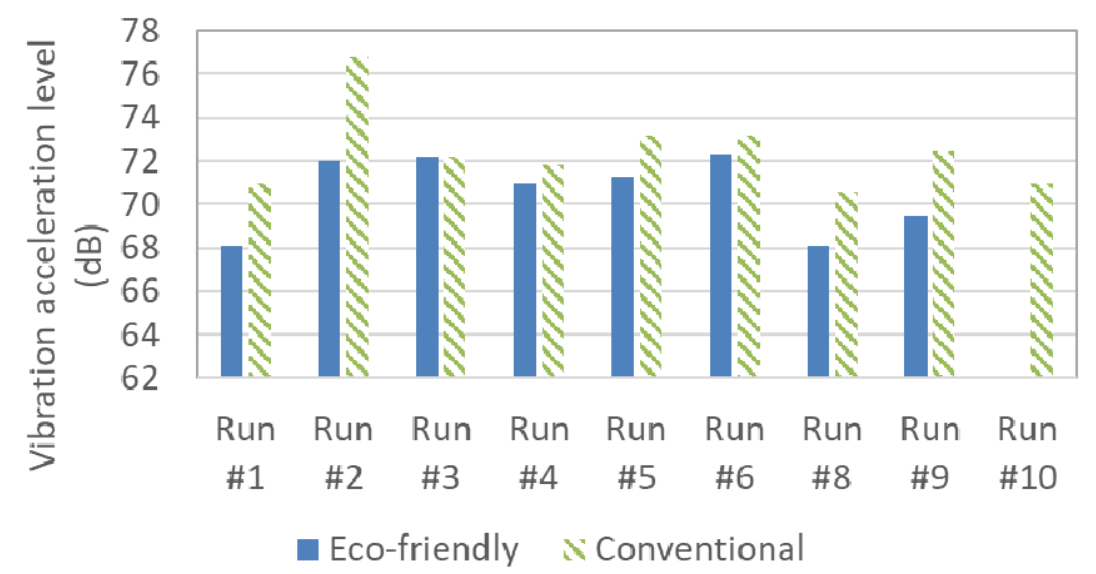

Figure 19. Vibration acceleration level on the slab floor based on the $1 / 3$ octave band analysis. 


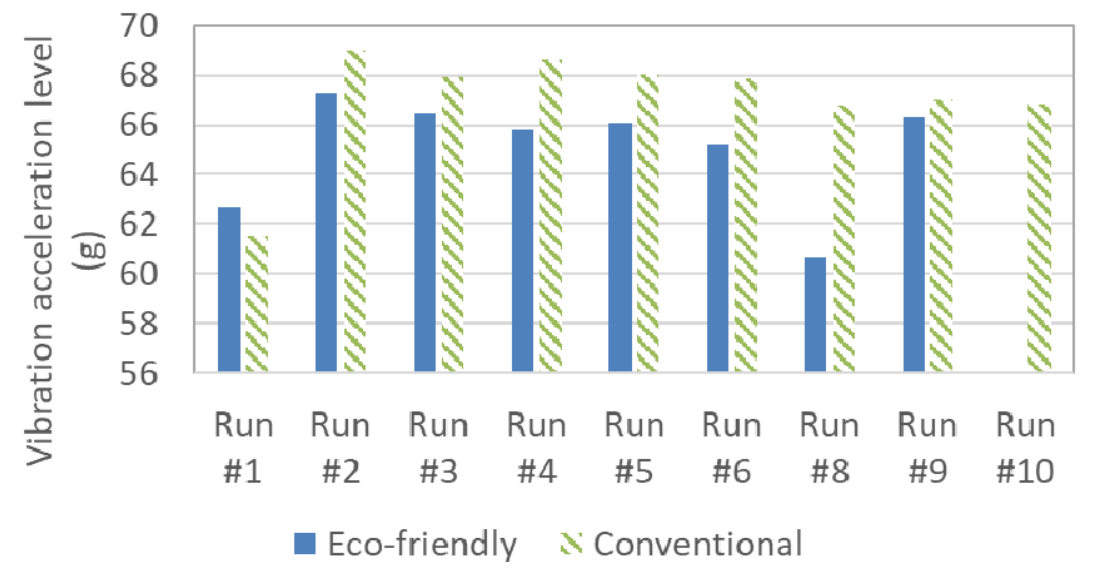

Figure 20. Vibration acceleration level on the tunnel walls based on the $1 / 3$ octave band analysis.

\section{Conclusions}

This study evaluated the field performance of the newly developed eco-friendly concrete slab system for the railroad track structure. In order to accommodate the increasing loading demands and maintenance cost, the ballastless track structure using a reinforced concrete slab was introduced and used in the railroad industry. At the same time, there has been a great interest to develop more environmentally friendly construction materials. This study utilized the newly developed eco-friendly concrete to manufacture an eco-friendly railroad concrete slab (eco-friendly B2S). The prototype of the eco-friendly B2S panels was manufactured and installed in one of the operating Seoul Metro subway lines and the field performance was evaluated. In order to compare its performance, a conventional B2S panel system was also installed side by side. Structural performance such as rail bottom stress, dynamic wheel vertical and lateral loads, track stiffness, and train-induced vibration and noise were measured. The measured performance of the eco-friendly B2S track structure indicated that the new system was compatible to the conventional B2S track system while the new system would not compromise the structural safety of the track system, since the rail bottom stress, the lateral displacement, and the $\mathrm{L} / \mathrm{V}$ ratio met the standard limits. In addition, the noise level was slightly reduced by using the eco-friendly B2S panels. Finally, with the eco-friendly concrete, $\mathrm{CO}_{2}$ emission was significantly reduced in manufacturing railway track structural components while the issue of the limited natural resource (e.g., river-sand) was addressed by recycling the industrial byproducts in South Korea. The eco-friendly concrete was developed with the aim of not compromising the structural integrity and durability of structural components of the rail track structural components while addressing some of the important environmental issues. The superior and/or compatible performance of the eco-friendly concrete is attributed to improved workability, durability, and denser microstructures with the higher 28-day minimum compressive strength.

Author Contributions: Conceptualization, T.K. and M.S.; methodology, T.K.; software, T.K. and M.S.; validation, T.K. and M.S.; formal analysis, T.K. and M.S.; investigation, T.K. and M.S.; data curation, T.K.; writing-original draft preparation, M.S.; writing—review and editing, T.K.; visualization, T.K. and M.S.; supervision, M.S.; project administration, T.K.; funding acquisition, T.K. All authors have read and agreed to the published version of the manuscript.

Funding: This research described herein was supported by a grant from R\&D Program of the Korea Railroad Research Institute (KRRI), Republic of Korea.

Conflicts of Interest: The authors declare no conflict of interest.

\section{References}

1. Oden, C.P.; Ho, C.L.; Kashani, H.F.; Smith, S.S. Ballast Fouling Measurement Tool: Phase 1; ORD 18-33; Federal Railroad Administration: Washington, DC, USA, 2018. 
2. Brown, M.; Li, D. Ground Penetrating Radar Technology Evaluation and Implementation: Phase 2; DOT/FRA/ORD-18/33; Federal Railroad Administration: Washington, DC, USA, 2018.

3. Tennakoon, N.; Indraratna, B.; Rujikiatkamjorn, C.; Nimbalkar, S.; Neville, T. The role of ballast-fouling characteristics on the drainage capacity of rail substructure. Geotech. Test. J. 2012, 35, 629-640. [CrossRef]

4. National Transportation Safety Board Railroad Accident Brief: Metro-North Railroad Derailment; NTSB/RAB-14/12; National Transportation Safety Board: Washington, DC, USA, 2014.

5. Riding, K.A.; Peterman, R.J.; Guthrie, S.; Brueseke, M.; Mosavi, H.; Koby, D. A Study of Environmental and Track Factors That Contribute to Abrasion Damage of Concrete Ties; DOT/FRA/ORD-19/38; Federal Railroad Administration: Washington, DC, USA, 2019.

6. Chen, Z.; Shin, M.; Andrawes, B.; Edwards, J.R. Parametric study on damage and load demand of prestressed concrete crosstie and fastening systems. Eng. Fail. Anal. 2014, 46, 49-61. [CrossRef]

7. Momeni, A.F.; Peterman, R.J.; Beck, B.T.; Wu, C.-H.J.; Bodapati, N.N.B. Effect of Concrete Release Strength on the Development Length and Flexural Capacity of Members Made with Different Prestressing Wires Commonly Used in Pretensioned Concrete Railroad Ties. In Proceedings of the 2015 Joint Rail Conference, ASME, San Jose, CA, USA, 23-26 March 2015.

8. Yu, H.; Marquis, B.P.; Jeong, D.Y. Failure analysis of railroad concrete crossties in the center negative flexural mode using finite element method. Proc. Inst. Mech. Eng. Part F J. Rail Rapid Transit 2017, 231, 610-619. [CrossRef]

9. Bastos, J.C.; Álvarez-Reyes, A.; Dersch, M.S.; Edwards, J.R.; Barkan, C.P.L. Laboratory Characterization of Structural Capacity of North American Heavy Haul Concrete Crossties. Transp. Res. Rec. J. Transp. Res. Board 2018, 2672, 116-124. [CrossRef]

10. Shin, M.; Yu, H. Numerical Evaluation of Splitting Performance of Prestressed Concrete Prisms with Larger Diameter Prestressing Wires. In Proceedings of the 2019 Joint Rail Conference, ASME, Snowbird, UT, USA, 10-12 April 2019; p. V001T01A018.

11. Bilow, D.; Randich, G. Slab track for the next 100 years. In Proceedings of the 2000 Annual Conference, American Railway Engineering and Maintenance-of-Way Association, Dallas, TX, USA, 10-13 September 2000; pp. 1-20.

12. Esveld, C. Modern Railway Track. In Proceedings of the First International Conference on Road and Rail Infrastructure, Opatijia, Croatia, 17-18 May 2010.

13. Lei, X.; Zhang, B. Analysis of dynamic behavior for slab track of high-speed railway based on vehicle and track elements. J. Transp. Eng. 2011, 137, 227-240. [CrossRef]

14. Pichler, D.; Gmbh, P.B. Ballastless Track Systems Experiences Gained in Austria and Germany. In Proceedings of the AREMA Conference, Indianapolis, IN, USA, 29 September-2 October 2013; pp. 81-100.

15. Tayabji, S.D.; Bilow, D. Concrete Slab Track State of the Practice. Transp. Res. Rec. 2001, 1742, 87-96. [CrossRef]

16. Koh, T.; Shin, M.; Bae, Y.; Hwang, S. Structural performances of an eco-friendly prestressed concrete sleeper. Constr. Build. Mater. 2016, 102, 445-454. [CrossRef]

17. Koh, T.; Shin, M.; Bae, Y.; Hwang, S. Experimental Study on transfer length of an eco-friendly prestressed concrete sleeper. Constr. Build. Mater. 2016, 109, 25-33. [CrossRef]

18. Koh, T.; Hwang, S. Field Evaluation and Durability Analysis of an Eco-Friendly Prestressed Concrete Sleeper. J. Mater. Civ. Eng. 2015, 27, B4014009. [CrossRef]

19. Kong, S.-Y.; Kim, S.-J.; Baik, C.-H. A Study of Optimum Thickness of B2S Track System under Variety of Rail support Stiffness and Axle load. In Proceedings of the 2009 Fall Conference of the Korean Society for Railway, Geongju, Korea, 13-14 November 2009; pp. 2685-2691. (In Korean).

20. Kong, S.-Y.; Oh, H.-W.; Kim, S.-J. The Reduction of Structure-borne Noise in an Elevated Station (Changdong Station) of Seoul Metro Line No. 1-4. In Proceedings of the 2007 Spring Conference of the Korean Society for Railway, Jeju, Korea, 17-18 May 2007; pp. 27-32. (In Korean).

21. Ministry of Land Infrastructure and Transportation. Performance Testing Specifications for Urban Railway Infrastructure; Ministry of Land Infrastructure and Transportation: Sejong City, Korea, 2013.

(C) 2020 by the authors. Licensee MDPI, Basel, Switzerland. This article is an open access article distributed under the terms and conditions of the Creative Commons Attribution (CC BY) license (http://creativecommons.org/licenses/by/4.0/). 